DOI: $10.4274 /$ tpa.46.37

\title{
Ergenlik çağında omurga sorunları
}

\section{Spine problems in adolescent}

\author{
Önder Aydıngöz \\ İstanbul Üniversitesi Cerrahpaşa Tıp Fakültesi, Ortopedi ve Travmatoloji Anabilim Dalı, İstanbul, Türkiye
}

\section{Özet}

Ergenin idiyopatik skolyozu, Scheuermann kifozu, spondilolizis ve spondilolistezis adölesan çağında ortopedik açıdan takip ve tedavi gerektiren en önemli omurga sorunlarıdır. (Türk Ped Arş 2011; 46 Özel Sayı: 65-7)

Anahtar sözcükler: Ergen, idiopatik skolyoz, scheuermann kifozu, spondilolizis, spondilolistezis

\section{Summary}

Adolescent's idiopathic scoliosis, Scheuermann kyphosis, spondylolysis and spondylolistesis are the most common spine problems of adolescence which needs orthopaedic treatment and follow-up. (Turk Arch Ped 2011; 46 Suppl: 65-7)

Key words: Adolescent, idiopathic scoliosis, scheuermann kyphosis, spondylolysis, spendylolistesis

\section{Giriş}

Ergenlik çağında sık görülen omurga sorunları idiopatik skolyoz, Schevermann kifozu ve spondilolizis-spondilolistezistir.

\section{İdiopatik skolyoz}

İdiyopatik skolyozda on yaştan sonra fark edilen eğrilik, hızlı büyüme döneminde genellikle hızla ilerler. Ergenlerin yaklaşık \%2'sinde $10^{\circ}$ yi aşan skolyoza rastlanır, ancak bunların içinden sadece \%5'inde eğrilik $30^{\circ}$ yi aşacak kadar ilerler (1). Hafif eğrilikler için görülme sıklığı kız ve erkeklerde yaklaşık eşitken, $30^{\circ}$ yi aşan eğriliklere kızlarda 8-10 kat daha fazla rastlanır $(2,3)$.

Etyoloji: Birçok çalsşmada skolyozlu kişilerin aile bireyleri arasında skolyoza rastlanma oranının normal populasyondan yüksek olduğu gösterilmiştir (1). Bunun yanında eş yumurta ikizlerinin her ikisinde de rastlanabilmesi de genetik teorileri desteklemektedir. Muhtemelen poligenik bir kalıtım mekanizması işlemekteyse de, bu konu aydınlanmış değildir.
Tavuklarda pineal bez ve melatonin düzeyleri ile skolyoz arasında ilişki kuran çalışmalar varsa da insanlarda bu durum çelişkilidir ve melatonin eksikliği ile skolyoz ilişkisi kesin olarak gösterilememiştir $(1,3)$.

Bulgular: Hastaları ve aileleri doktora getiren esas nedenler genellikle deformiteye bağlı kozmetik problemler ve ileri olgularda duruş bozuklukları ve gövde dengesizlikleridir $(1,3)$.

Ağrı önde gelen bir yakınma değildir. Ağrı varlığında buna neden olabilecek diğer nedenler (tümör, enfeksiyon, disk hernisi, vb) araştııımalıdır. Özellikle $60-70^{\circ}$ yi aşan eğriliklerde çabuk yorulma, nefes darlığı gibi yakınmalar olabilir.

Fizik bakı: Hastanın gövde dengesi incelenmeli, her iki omuz ve memeler arasında seviye farklılığı olup olmadığı, pelvisin eğimi olup olmadığı araştııımalıdır. Hastaya yandan baklarak torasik kifoz ve lomber lordoz incelenmelidir. Hasta öne doğru eğilerek eğriliğin tepesinde rotasyon nedeniyle kaburgaların arkaya itilmesine bağı çıııntı olup olmadığı kontrol edilmelidir. Ergen idiopatik skolyozunda nörolojik 
sorun beklenmese de, tüm hastalarda detaylı bir nörolojik muayene mutlaka yapılmalıdır. Hastaların cinsel gelişimleri incelenmeli, kız çocukların adet görüp görmedikleri, ilk adet tarihleri de kaydedilmelidir. Hızlı büyüme dönemi bitmemiş çocukların eğrilik ilerlemesi açısından daha riskli oldukları unutulmamalıdır $(1,3)$.

Radyolojik inceleme: Skolyozlu hastalarda tüm omurganın baş ve pelvisle beraber görüldüğü boy grafileri ile değerlendirme yapılır. Bunlar ayakta çekilen AP ve lateral grafiler, yatarak çekilen sağa ve sola eğilme grafileri ile traksiyonda çekilen grafilerdir (1). Eğriliğin derecesi Cobb metoduyla ölçülür. Hastanın kemik gelişimini değerlendirmek için ise iliak apofizin durumu incelenir. Lateral grafilerde omurganın sagital dengesi, yana eğilme ve traksiyon grafilerinde ise primer ve sekonder eğriliklerin fleksibilitesi değerlendirilir. Eğrilik derecesinin nasıl değiştiği, omurga dengesinde bozulma olup olmadığı seri grafiler ile takip edilir. Skolyoz ya da kifoz nedeniyle boy grafisi yerine torakolomber ya da lumbosakral grafiler istenerek hastalar fazladan radyasyona maruz bırakılmamalıdır.

Ayırıcı tanı: Skolyozun idiopatik olduğuna karar vermeden önce diğer skolyoz nedenleri dışlanmalıdır. Hastalarda doğumsal bir omurga anomalisi olmadığından emin olunmalı, nöromusküler problemlere bağlı olmadığı gösterilmelidir. Ayrıca Marfan sendromu ve nörofibromatozis gibi hastalıkların bulunmadığından ve eğriliğin posttravmatik olmadığından emin olunmalıdır. Özellikle ağrılı eğriliklerin tümör ve enfeksiyonlara sekonder olabileceği de akılda bulundurulmalıdır (1-3).

Tedavi: $20^{\circ}$ nin altındaki eğrilikler sadece takip edilir, $20-40^{\circ}$ arasındaki eğriliklerde korse tedavisi uygulanırken, $40-45^{\circ}$ nin üzerinde cerrahi endikasyonu vardır. Ancak tedavi tipini belirlemede tek kriter eğriliğin derecesi değildir; hastanın kemik gelişim düzeyi, kalan büyüme kapasitesi, omurganın dengesi, eğriliğin fleksibilitesi ve ilerleme hızı gibi etkenler de göz önünde bulundurulur. Hasta korseliyken belirgin düzelme elde edilebilmesine rağmen, korse tedavisinde temel amaç eğriliği düzeltmekten çok büyüme tamamlandığında ameliyat endikasyon sınırının altında dengeli bir omurga elde etmektir. Cerrahi tedavide ise amaç eğriliği düzeltmek, dengeli bir omurga elde etmek ve yeniden ilerlemesini önlemektir. Bu amaçlarla anterior ya da posterior omurga enstrumantasyonları ve füzyon yöntemleri uygulanır (1-3).

\section{Scheuermann kifozu}

Genel populasyonda görülme sıklığı \%0,4-\%8,3 arasında bildirilmiştir $(4,5)$. Etyoloji konusundaki belirsizlik halen sürmektedir. Scheuermann hastalığının bazı ailelerde daha sık görüldüğü değişik yazarlarca bildirilmiş, ayrıca monozigotik ikizlerde de hastalık gösterilmiştir $(6,7)$. Hastalığın otozomal dominant geçiş gösterdiği de öne sürülmüştür (7-9).
Muhtemelen Scheuermann hastalığı patogenezinde birçok etken birarada yer almaktadır.

Bulgular: Hastalar genellikle kozmetik problemle başvururlar (10). Daha çok puberte civarında ortaya çıkan torakal ya da torakolomber yerleşimli bu deformitenin genellikle kötü postüre bağlanması tanıda gecikmelere yol açmaktadır (11). Bunun yanında hastaların yaklaşık yarısında ağrı bulunabilir. Ağrı, 1. ve 2. lomber omurun kifoza dahil olduğu olgularda daha da yüksek orandadır; sürekli ve engelleyici olmaktan çok, ara, ara olan düşük yoğunluklu bir karakterdedir $(10,11)$. Genellikle uzun süreli oturma ya da egzersizin neden olduğu ağıı, dinlenmekle geçer ve daha çok tepe civarında hissedilir $(5,11,12)$. Büyüme döneminin bitmesi ile ağrı genellikle ortadan kalkar (12).

Fizik bakı bulguları: Inspeksiyonda torasik kifozda ve lomber lordozda artış görülür. Hasta öne eğildiğinde torasik kamburluğun arttığı gözlenir (10). Hasta pron pozisyonda iken torasik hiperekstansiyonla kifozu genellikle tam düzeltemez, oldukça sabit bir deformitesi vardır. Lomber lordozdaki artış ise genellikle yapısal değildir, öne eğilmekle düzelir $(5,11)$. Minimal bir skolyoz gözlenebilir. Hastaların yaklaşık 1/3'ünde kifoz bölgesinde hassasiyet ve kas spazmı olabilir. Ayrıca omuz kuşağı ön kasları ile iliopsoas ve hamstringlerde gerginlik bulunabilir $(10,11)$. Tüm hastalarda detaylı nörolojik muayene yapılmalıdır. Özellikle ileri derecelere varmış olgularda nadir olarak omurilik basısına bağı spastik paraparezi bulgularına (ataksi, hiperrefleksi) rastlanabilir. Omurilik basısı açısal deformiteye ya da eğrilik tepesinde torasik disk herniasyonuna bağlı olabilir $(10,11)$.

Radyolojik bulgular: Scheuermann kifozunun radyolojik tanı kriterleri şunlardır: (1) $45^{\circ}$ yi aşan torasik kifoz, (2) Eğriliğin tepesinde en azından 3 komşu vertebrada $5^{\circ}$ yi aşan kamalaşma, (3) Vertebralarda anormallikler (epifiz plaklarında düzensizlik ve düzleşme, Schmorl nodları, disk mesafesinde azalma, apikal bölgede korpuslarda anteroposterior elongasyon) (5).

Ayırıcı tanı: Postural kifoz, doğumsal kifoz, kemik displazilerine bağı kifoz deformiteleri, travmatik kompresyon kırıkları, ankilozan spondilit ve omurga enfeksiyonları ile tümörlerine bağlı gelişen vertebra düzensizlikleri ve deformiteler göz önünde bulundurulmalıdır $(5,11)$. Hasta değerlendirilirken, gerekirse bu olasılıklara yönelik ileri tetkikler yapılmalıdır.

Tedavi: Henüz iskelet gelişimi süren hastalardaki $65^{\circ}$ den küçük fleksibl eğriliklerde korse tedavisi ile iyi sonuçlar alınabilmekte, eğriliğin ilerlemesini önlemenin yanında düzelmeler de sağlanabilmektedir (1). $70-75^{\circ}$ nin üzerindeki eğriliği olan ya da $65^{\circ}$ üzerinde cerrahi dışı yöntemlerle ağrısı rahatlatılamayan hastalarda ameliyat endikasyonu vardır. Cerrahi anterior, posterior ya da kombine yöntemlerle gerçekleştirilebilir. 


\section{Spondilolizis-spondilolistezis}

Spondilolizis pars interartikülaristeki defekti, spondilolistezis ise bir vetebranın alttaki komşu vertebra üzerinde öne doğru kaymasını ifade eden terimlerdir. Spondilolizis 5 yaşın altında nadirdir, genellikle 7-8 yaş üzerinde görülür. Görülme sıklığı yaşla artarak 20 yaş civarında yaklaşık \%6'lık bir platoya ulaşır (13). Spondilolizisli hastaların yaklaşık \% 8 'i 20 yıl içinde çoğu düşük dereceli olan spondilolistezise dönüşür (14).

Etyoloji: Çocuklarda ve ergenlerde belin tekrarlayan hiperekstansiyonunun sık yapıldığı etkinlik ve sporların (dans, jimnastik) spondilolizis gelişimi için önemli bir risk etkeni olduğu bilinmektedir (13). Bu bölgenin yorgunluk kırıkları etyolojide sorumlu tutulmaktadır. Hastaların ailelerinde de bu duruma daha sık rastlanması ve ırklar arası farklılıklar gibi nedenler mekanizması tam açıklanamamış bir genetik mekanizmayı düşündürmektedir.

Bulgular: Spondilolizis ve spondilolistezis çocuk ve ergenlerde bel ağrısının en sık nedenleridir (13). Ancak buna rağmen spondilolizis ve spondilolistezisli çocukların ancak \%10-15 kadarında bulgular vardır $(15,16)$. Bulguların başlangıcı genellikle ergenin hızı büyüme dönemine rastlar. Radiküler ağrı ve nörolojik sorunlar nadirdir ve genellikle ciddi kaymalarda görülür.

Fizik bakı bulguları: Hamstring kaslarında gerginlik ve buna bağlı duruş ve yürüyüş anormallikleri, düz bacak kaldırmada kısıtlılık olabilir $(13,15)$. Ciddi kaymalarda palpasyonda belin arkasında bir basamak hissedilebilir ve transvers abdominal bir çizgi gözlenebilir. Sinir kökü basısı varsa, kas güçsüzlüğü, his kaybı, anormal refleksler bulunabilir.

Radyolojik bulgular: Pars defektleri lateral ve oblik lumbosakral grafilerde görülebilir, kaymayı ise en iyi lateral grafiler gösterir (13). Bilgisayarlı tomografi pars defektlerini ve bunlardaki iyileşmeyi göstermede etkili iken nöral kompresyonu göstermede manyetik rezonans görüntüleme daha değerlidir.

Tedavi: Büyüme sonlanana kadar kayma ilerlemesi açısından 6 ayda bir radyolojik olarak takip gerekir (13). Hastaların çoğunda hiperekstansiyona zorlayan etkinliklerin kısıtlanması, antilordotik korseler ve fizyoterapi etkilidir. Gergin olan hamstringleri ve lumbodorsal fasyayı gerici egzersizlerle paravertebral kasları ve karın kaslarını güçlendirici egzersizler verilir. Kısa süreli analjezik uygulamaları yapılabilir. Çoğu hasta bu tedavilerden yarar görür. Bunlardan yarar görmeyen hastalar ve büyüme döneminde $\% 50$ 'nin üzerinde kayması olan çocuklar cerrahi tedavi adayıdırlar.
Cerrahi tedavide pars interartikülaris tamirlerinden, izole dekompresif prosedürlerden, redüksiyon ameliyatlarından anterior, posterior ya da kombine füzyon girişimlerine ya da L5 vertebrektomiye kadar değişik seçenekler vardır $(13,15)$.

\section{Kaynaklar}

1. Newton PO, Wenger DR. Pediatric Spinal Deformity. In: Fardon DF ed(s). AAOS Orthopaedic Knowledge Update-Spine 2. Illinois: AAOS, 2002: 361-76.

2. Lenke L, Dobbs MB. Idiopathic scoliosis. In: Frymoyer JW ed(s). The Adult and Pediatric Spine. Philadelphia: Lippincott Williams and Wilkins, 2004: 337-60.

3. King HA. Idiopathic scoliosis. In: Herkowitz HN ed(s). RothmanSimeone The Spine. Philadelphia: Saunders, 2006: 515-34.

4. Hu SS, Bradford DS. Juvenile kyphosis. In: An HS (ed). Principles and Techniques of Spine Surgery. Baltimore: Williams and Wilkins, 1998: 239-48.

5. Lowe TG. Scheuermann's disease. In: Bridwell HB ed(s). The Textbook of Spinal Surgery. Philadelphia: Lippincott-Raven Publishers, 1997: 1173-98.

6. Linthoudt D, Revel M. Similar radiographic lesions of localized Scheuermann's disease of the lumbar spine in twin sisters. Spine 1994; 19: 987-9.

7. McKenzie L, Sillence D. Familial Scheuermann disease: a genetic and linkage study. J Med Genet 1992; 29: 41-5. (Full Text) / (PDF)

8. Axenovich TI, Zaidman AM, Zorkoltseva IV, Kalashnikova EV, Borodin PM. Segregation analysis of Scheuermann disease in ninety families from Siberia. Am J Med Genet 2001; 100: 275-9. (Abstract) / (Full Text) / (PDF)

9. Halal F, Gledhill RB, Fraser FC. Dominant inheritance of Scheuermann's juvenile kyphosis. Am J Dis Child 1978; 132: 1105-7. (Abstract)

10. Bradford DS. Juvenile Kyphosis. In: Lonstein JE ed(s). Moe's Textbook of Scoliosis and other deformities. Philadelphia: W.B. Saunders, 1995: 349-67.

11. Tachdijan MO. Scheuermann's Juvenile Kyphosis. In: Tachdijan MO (ed) Pediatric Orthopedics. WB Philadelphia: Saunders, 1990: 2380-90.

12. Lowe TG. Scheuermann's disease. Orthop Clin North Am 1999; 30: 475-87.

13. Molinari RW, Lenke LG. Pediatric spondylolysis and spondylolisthesis. In: Frymoyer JW ed(s). The Adult and Pediatric Spine. Philadelphia: Lippincott Williams and Wilkins, 2004: 399-423.

14. Saraste H. Long-term clinical and radiological follow-up of spondylolysis and spondylolisthesis. J Pediatr Orthop 1987; 7:631-8. (Abstract)

15. Connoly PJ, Fredrickson BE. Surgical management of isthmic and dysplastic spondylolisthesis and spondylolysis. In: Fardon DF ed(s). AAOS Orthopaedic Knowledge Update - Spine 2. Illinois: 2002: 353-60.

16. Fredrickson BE, Baker D, McHolick WJ, Yuan HA, Lubicky JP. The natural history of spondylosis and spondylolisthesis. J Bone Joint Surg Am 1984, 66: 699-707. (Abstract) 